\title{
NOVAS NARRATIVAS PARA O INVESTIMENTO SOCIAL E ACESSO A RECURSOS NAS PERIFERIAS
}

\author{
Cássio Aoqui \\ Diana Mendes dos Santos
}

\section{// resumo}

Em se tratando de investimento social privado (ISP), muitas histórias existem sobre a transferência de recursos entre financiadores e organizações da sociedade civil, mas pouco se fala sobre como essas parcerias se dão da perspectiva de quem é financiado e menos ainda quando se trata de movimentos sociais e coletivos das periferias. Nesse contexto, este artigo investiga os fatores críticos de acesso a recursos a partir da perspectiva de lideranças periféricas da cidade de São Paulo. Para isso, acompanhou-se, ao longo de um ano, o grupo Potências Periféricas, que propõe espaços de diálogo entre coletivos, empreendedores, movimentos sociais e organizações sociais das periferias e financiadores, visando trocas horizontais que quebrem barreiras de entendimento mútuo. Com base na sistematização de três encontros e uma imersão, identificaram-se dois fatores e 24 subfatores críticos de sucesso para o ISP: o primeiro relacionado a mudanças de aspectos culturais e comportamentais por parte dos financiadores (mudanças de paradigma e de know-how e visão empática); o segundo a respeito de aspectos técnicos e táticos do cotidiano da parceria entre investidores e investidos (comunicação, processos de seleção e relacionamento). São esses elementos que, do ponto de vista de lideranças da periferia, podem qualificar a relação com investidores sociais.

palavras-chave: investimento social privado | redução de desigualdades | lideranças periféricas | acesso a recursos. 


\section{OS ARTIGOS GIFE}

A série Artigos GIFE publica reflexões e análises de pesquisadores brasileiros de diferentes áreas do saber com o objetivo de estimular, ampliar e disseminar a produção de conhecimento qualificado sobre o campo da filantropia, do investimento social privado e da sociedade civil no Brasil.

A partir da premissa de que a produção de conhecimento sobre esses temas tem um papel fundamental na expansão, diversificação e qualificação da ação pública pela sociedade, a iniciativa também pretende contribuir para ampliar as conexões entre o setor, as universidades e os centros de pesquisa, promovendo e apoiando o envolvimento de novos atores com a temática e a circulação ampliada de ideias em torno dela.

Este texto integra a segunda edição dos Artigos GIFE, que propõe a publicação mensal de artigos selecionados por meio de chamada pública e convite a autores especialistas em temáticas específicas e relevantes para o setor, buscando apoiar e fomentar a produção de conhecimento sobre o investimento social no Brasil.

O Grupo de Institutos Fundações e Empresas (GIFE) é uma organização sem fins lucrativos que reúne associados de origem empresarial, familiar ou independente que investem em projetos de interesse público. Criado em 1989 como grupo de troca e colaboração e institucionalizado em 1995 por 25 organizações, tornou-se referência no campo da filantropia e do investimento social privado no Brasil.

Nesses mais de 20 anos de atuação, tem contribuído para o fortalecimento de práticas e ações a serviço do bem comum no país, trabalhando para expandir, qualificar e fortalecer o investimento social privado, diversificar e ampliar atores e recursos, criando referências e estimulando boas práticas de gestão, bem como articulando o setor com a sociedade e a agenda pública. Atualmente, o GIFE reúne mais de 150 associados que, somados, aportam mais de $\mathrm{R} \$ 3$ bilhões por ano em projetos próprios e no apoio a projetos de terceiros. 
As histórias importam. Muitas histórias importam. As histórias foram usadas para espoliar e caluniar, mas também podem ser usadas para empoderar e humanizar. Elas podem despedaçar a dignidade de um povo, mas também podem reparar essa dignidade despedaçada. [...] quando rejeitamos a história única, quando percebemos que nunca existe uma história única sobre lugar nenhum, reavemos uma espécie de paraíso (ADICHIE, 2019, p. 32-33).

Concordamos com a escritora nigeriana Chimamanda Ngozi Adichie ao evidenciar o perigo de uma história única. Aquela história única que cria estereótipos, cujo problema "não é que sejam mentira, mas que são incompletos" (2019, p. 33). Em um país de imensas desigualdades socioeconômicas como o Brasil, histórias únicas e estereótipos sobressaem nas mais diferentes formas de domínio, cooptação e subjugação. Em matizes e nuances ora perigosamente sutis, ora absurdamente escancaradas.

Em se tratando de investimento social privado (ISP), muitas histórias existem sobre a transferência de recursos entre empresas, fundações, institutos e organizações da sociedade civil (OSC), mas pouco se fala sobre como essas parcerias se dão da perspectiva de quem é financiado e menos ainda quando se trata de movimentos sociais e coletivos das periferias na outra ponta - a de quem recebe os recursos.

Nos principais estudos sobre ISP há poucas informações específicas sobre esse público e território. Por exemplo, no último Censo GIFE (GIFE, 2016), considerando apenas o recorte de dados sobre os três projetos/ programas declarados como prioritários pelos respondentes, percebe-se que, de uma base total de 116 organizações, 75,9\% não faziam distinção de grupos étnicos, raciais, religiosos ou povos/ comunidades tradicionais e 56\% não faziam distinção de território na realização de suas ações de investimento social. Algumas organizações utilizaram-se da alternativa "outros" para especificar outras características dos beneficiários de seus projetos/programas, sendo que são citados apenas sete vezes especificamente moradores de área de vulnerabilidade social/ periferia urbana e uma vez escolas de área de vulnerabilidade social/ periferia urbana. Nessa mesma alternativa há ainda uma menção a lideranças locais mapeadas nos territórios e três menções para população de baixa renda. Não se sabe, porém, quantas organizações de fato trabalham com esses temas, uma vez que essas opções não constavam na listagem de alternativas dessa questão do Censo GIFE 2016.

1 Este artigo contou com o apoio de Sofia Martin Melazzo e a revisão técnica de Letícia Pereira e Rafael Bernardo Carvalho, bem como a validação do grupo Potências Periféricas. 
No que se refere a parcerias formais estabelecidas para os três projetos/ programas declarados como prioritários pelos respondentes, do total de 116 respondentes do Censo (GIFE, 2016), 71,6\% as mantinham com organizações da sociedade civil/ comunitárias/ de base; 30,2\% com associações de moradores; e $15,5 \%$ com movimentos sociais e coletivos.

Ainda nessa linha, uma proxy no mesmo estudo que pode nos ajudar a entender o baixo nível de financiamento de coletivos e movimentos periféricos é o percentual de institutos e fundações com conselheiros negros em sua governança, apenas 3\% (GIFE, 2016) - ou seja, estamos falando de um desequilíbrio ainda estrutural.

Em convergência com esses dados do campo do ISP, o que notamos empiricamente em oito anos de trabalho, seja na atuação direta com coletivos e lideranças periféricas, seja pesquisando as relações do ISP, é que ainda é, de fato, escasso o direcionamento de investimento social para as periferias. Entretanto, ainda que minoria, temos visto cada vez mais fundações e institutos progressistas e de vanguarda colocando-os na agenda de prioridades, muitas vezes nas perspectivas de valor compartilhado (PORTER e KRAMER, 2011) e de impacto coletivo (KANIA e KRAMER, 2011).

Em relação ao impacto coletivo, Silvia Barros (2019) aponta cinco condições-chave para alcançá-lo: 1) a construção de uma agenda comum; 2) o estabelecimento de métricas para acompanhar os esforços realizados entre os atores; 3) o desenvolvimento de atividades diferenciadas, mas de reforço mútuo; 4) a comunicação contínua; e 5) a constituição de uma organização central que dê suporte para a iniciativa e coordene as ações que se fizerem necessárias. Ou seja, o impacto coletivo só é alcançado a muitas mãos.

Partimos desse conceito para a criação do coletivo Potências Periféricas, formado entre julho e agosto de 2018 a partir dos esforços de três atores intermediários e desenvolvedores do campo de impacto social no Brasil - ADE SAMPA, ponteAponte e Sense-Lab -, provocados pela interlocução com diversas lideranças periféricas paulistanas. Ao longo de 2018, mais três atores somaram forças à iniciativa: Fundação Tide Setubal, Fundo ZL Sustentável e Instituto Jatobás. Os seis atores, todos com anos de experiência em investimento social, tornaram-se então os facilitadores de um coletivo de coletivos, formado por 17 organizações e coletivos periféricos. São eles: Agência Mural de Jornalismo das Periferias, Ateliê Cendira, Associação de Pais Funcionários do Tribunal de Justiça (APAJE), Coletivo Abebé, Coletivo Cultural Esperança Garcia, Coletivo Cultural Marginaliaria, Coletivo Encrespad@s, Coletivo É Bom De Ver Cidade, Cooperativa Habitacional Central do Brasil (Coohabras), Énois - Agência de Jornalismo, Emperifa, Feminismo Comunitário Real Parque, Instituto Favela da Paz, LabHacker, Liga Solidária, Movimento Interativo de Arte Cultura e Ação Social e Projeto Viela.

Com o objetivo de fomentar chamadas públicas mais inclusivas, para que líderes de projetos das periferias da cidade de São Paulo consigam, efetivamente, acessar recursos disponibilizados por editais, desafios e prêmios em curso no Brasil, o Potências propõe espaços de diálogo entre líderes periféricos, coletivos, empreendedores, movimentos sociais, organizações sociais e financiadores, visando trocas horizontais baseadas na empatia e que quebrem possíveis barreiras de entendimento mútuo. Além disso, momentos de capacitação para as organizações participantes e a produção de materiais para divulgar informações - tanto entre os projetos periféricos quanto das periferias para os financiadores - são pontos que invertem a lógica tradicional, um dos destaques e diferenciais do grupo.

Para promover essa discussão, entre agosto de 2018 e julho de 2019 foram realizados três encontros, com cerca de 4 horas cada um, e uma imersão de dois dias com os atores participantes. As principais descobertas relatadas neste artigo são fruto de sistematização analítica das conversas e reflexões que emergiram nesse período, utilizando métodos como grupos focais facilitados e/ou autogestionados.

Assim, este artigo resulta da investigação de fatores críticos de acesso a recursos a partir da perspectiva de lideranças periféricas, mais especificamente das periferias da cidade de São Paulo. Nosso objetivo foi levantar quais são os desafios e as possíveis soluções em um caminho coletivo e como fazer o ISP se alinhar aos contextos periféricos de maneira mais genuína - e em um cenário de esfacelamento de direitos fundamentais. 
O primeiro capítulo faz um breve resgaste histórico, especialmente brasileiro, da área social e de como foi e é a trajetória de movimentos sociais, coletivos e organizações. Também lança luz para literaturas não acadêmicas buscando trazer algumas perspectivas de agentes periféricos. O segundo capítulo detalha a metodologia dos encontros e imersão com o grupo Potências Periféricas e aponta os principais fatores críticos em relação ao ISP descobertos e reverberados por meio dessas ações. Por fim, as considerações finais ressaltam a importância da escuta empática, da comunicação efetiva entre os lados e da coerência técnica antes de serem propostos investimentos em um projeto/ programa.

\section{CONTEXTO HISTÓRICO: DA LITERATURA ACADÊMICA À PERIFÉRICA}

Ainda que não em sua totalidade, muitos dos coletivos periféricos mencionados neste estudo surgem no bojo dos "novos movimentos sociais", como um desdobramento dos tempos atuais (zeitgeist) relacionados a movimentos globais (viabilizados pelas tecnologias de informação e comunicação), que se evidenciam, entre outros, na Primavera Árabe (BIEKART e FOWLER, 2012).

A nosso ver, contudo, esse fenômeno, no caso brasileiro, vem na esteira de um processo histórico único e indissociável, do qual optamos por fazer um recorte temporal a partir da ditadura militar neste item. É nesse período que emergem os movimentos sociais, que passam a ser estudados na década de 1970, frutos de uma conjuntura intelectual e política específica, que coincide com o avanço do autoritarismo sobre vários países latino-americanos e sucede os temas típicos dos anos 1960: a marginalidade e a dependência.

Associações de bairro, grupos de moradores, clube de mães, Comunidades Eclesiais de Base (CEB), ao se tornarem mais numerosos e atuantes, são vistos como formas autênticas de participação popular, onde a democracia interna garante tanto a manifestação de uma vontade coletiva quanto o confronto direto com as políticas públicas autoritárias (CARDOSO, 1987, p. 28).

Esse ambiente, de acordo com Paula (2005), provou-se fértil para promover a articulação de grupos em torno de questões que interferem substancialmente na qualidade de vida individual e coletiva, originando reivindicações populares com o poder público. Emergiram demandas por bens de uso coletivo, como transporte, habitação, abastecimento e saneamento básico, saúde e creche.

Paralelamente, constituíam-se os primeiros centros populares, espaços criados por militantes políticos para facilitar sua atuação nas CEB e nas bases comunitárias em atividades como as de assessores, educadores e organizadores da mobilização popular. A partir da década de 1980, esses centros populares também passaram a ser denominados organizações não governamentais (PAULA, 2005, p. 39).

Paulatina e organicamente, parte dos movimentos sociais passou a se inserir institucionalmente, combinando características - como aumento da complexidade da estrutura organizacional e participação dos militantes, relações com instituições políticas e outros movimentos e interações cooperativas e contestatórias - na relação sociedade-Estado (CARLOS, 2011).

Chega-se assim às duas últimas décadas do século XX, no qual a cena de debates se desenrolou sob o desenvolvimento social no Brasil e passou a ser ocupada gradativamente por uma multiplicidade de atores:

[...] as ONG, que reassumiram sua posição de defesa de direitos e interesses; as associações, principalmente aquelas que agregam comunidades populares; as entidades beneficentes e filantrópicas; e, surpreendentemente, as empresas, as associações empresariais, as fundações e os institutos vinculados a corporações (FISCHER, 2002, p. 43).

Mais recentemente, novas formas organizacionais começam a ganhar corpo. Uma nova geração de lideranças no campo social desperta uma forma diferenciada de engajamento em temas de cidadania, que vem sendo alcunhada por pensadores e pesquisadores como "novos movimentos sociais" ou 
“ativismo cívico", entre outras denominações (BIEKART e FOWLER, 2012, 2013; CASTELLS, 2012; SECCO, 2013). Desde 2010, esses processos vêm se desdobrando nas grandes cidades do mundo: ruas e praças foram tomadas por cidadãos auto-organizados que exigem direitos políticos e sociais. As imagens de protesto foram televisionadas, baixadas e rapidamente distribuídas - aparentemente em diversos locais e tipos de ativismo velozmente conectados e falando uns com os outros.

Será que essa escala e momentum sinalizam um ponto de inflexão em uma "globalização de desafeto"? Estamos testemunhando o surgimento de um novo grupo etário de ativistas, semelhante à "geração de 1968"? Quais foram os elementos comuns, e que energia estava dirigindo os ativismos das praças? (BIEKART e FOWLER, 2013, p. 527).

Os autores, que estudaram inclusive os protestos ocorridos em junho de 2013 no Brasil, concluem que os ativismos contemporâneos representam uma clara mudança no caráter de engajamento cívico, na medida em que navegam em ondas criadas pela disponibilidade e uso crescentes das mídias sociais e por um conjunto comum de direitos com base em demandas.

Assim, ainda que alguns autores considerem "movimentos sociais, coletivos populares, fóruns e redes de movimentos, organizações comunitárias e de base" como organizações da sociedade civil (TEODÓSIO, 2014, p. 128), vale ressaltar que muitos desses coletivos não são institucionalizados formalmente, não se reconhecem dessa forma e hoje buscam um lugar de fala próprio e apropriado (RIBEIRO, 2017). Em certos casos, consideram a institucionalização até mesmo como forma de cooptação (LAVALLE, CASTELLO e BICHIR, 2004).

Além disso, em um contexto marcado por relações desiguais de poder, faz-se necessário ponderar sobre o lugar de fala. Djamila Ribeiro expõe que esse é um conceito impreciso, já trazido não apenas por autoras negras, mas por exemplo pela indiana Gayatri Chakravorty Spivak. É importante refletir sobre quem pode falar em uma sociedade em que o discurso legitimado é o do homem branco heterossexual. A partir dessa legitimação, a deslegitimação do discurso do "outro" ocorre de maneira automática, provocando um silenciamento adotado em uma estrutura de poder racial e de gênero. Como outras vozes são consideradas nesse contexto? Como o "outro" é considerado?

Quando estamos falando de lugar de fala, estamos falando de lugar social, de localização de poder dentro da estrutura. [...] Todo mundo tem um lugar de fala porque está localizado socialmente, mas como se fala a partir do seu lugar sobre outras questões (RIBEIRO, 2017, s/p).

Partimos da premissa de que, para entender diferentes movimentos sociais, organizações e/ ou coletivos ao longo da história e atualmente, é preciso ouvir o que eles têm a dizer a partir da perspectiva de quem são e onde atuam. Não causa surpresa o fato de que uma busca nas principais bases de journals indexados pouco traz sobre o tema "investimento social nas periferias" - e muito menos estudos no mainstream acadêmico realizados por pesquisadores periféricos. Porém, o que conecta todos os coletivos é a diversidade de suas histórias, que partem de perspectivas múltiplas. Por isso lançamos mão da literatura não acadêmica e citamos o jovem escritor periférico Alexandre Ribeiro (2019), ao fazer a introdução de seu livro em duas vias - uma para o jovem leitor periférico e outra para o leitor "branco-classe-média-alta":

[...] a ideia aqui não é fazer distinção, mas sim sermos diretos. [...] o que é literatura? Histórias que respeitam regras, mas não respeitam diversidade? O nosso respeito aos clássicos caminha de mãos dadas com nosso ódio por um Brasil fundado na desigualdade. Acreditamos em tempos onde a literatura é um direito. E antes de ser direito, é peito aberto. Não é regra. Exercido por todos e sonhado em conjunto. Histórias. No plural mesmo. Plurais e incontingentes (RIBEIRO, 2019, p. 4).

Outra referência é Carolina Maria de Jesus. Já se passaram mais de 30 anos desde que escreveu seu livro, Quarto de Despejo. 
A cidade tem outra cara, esparramada para muito além da avenida Marginal. E a favela do Canindé, onde viveu Carolina Maria de Jesus, na rua A, barraco $n^{\circ}$ 9, multiplicou-se em dezenas, centenas de outras. Assim, Quarto de Despejo não é um livro de ontem, é de hoje. Os quartos de despejo, multiplicados, estão transbordando (DANTAS, 1993, s/p).

Carolina, que trabalhou como catadora de lixo antes de se sagrar escritora, nos provoca narrando a realidade por ela vivida e nos convida a pensar o que queremos saber das pessoas em situação de maior vulnerabilidade e como nos relacionamos com elas.

\footnotetext{
Eu sei que existe brasileiros aqui dentro de São Paulo que sofre mais do que eu. Em junho de 1957 eu fiquei doente e percorri as sedes do Serviço Social. Devido eu carregar muito ferro fiquei com dor nos rins. Para não ver meus filhos passar fome fui pedir auxilio ao propalado Serviço Social. Foi lá que eu vi as lagrimas deslisar dos olhos dos pobres. Como é pungente ver os dramas que ali se desenrola. A ironia com que são tratados os pobres. A unica coisa que eles querem saber são os nomes e os endereços dos pobres (JESUS, 2014, p. 42)².
}

Essas questões emergem de um Brasil repleto de desigualdades, muitas das quais levaram diversos coletivos periféricos a se organizarem a fim de potencializar sua atuação e poder de transformação, abrindo os olhos de parte dos investidores sociais para esse movimento. Nossa vontade é fortalecer o debate de como atores periféricos podem acessar tais recursos, de forma mais estruturada e com mais diálogo, buscando escrever várias histórias sobre essa história. E coletamos, narramos, redigimos e descrevemos essas histórias não do lugar do pesquisador imparcial, positivista, apartado da realidade. Buscamos um paradigma de pesquisa construtivista-decolonial, acreditando que múltiplos conhecimentos coexistem quando intérpretes igualmente competentes discordam ou concordam em razão de fatores sociais, políticos, culturais, econômicos, étnicos e de gênero que os diferenciam. Tais construções estão sujeitas a revisão e debate contínuo, em que o conhecimento surge da somatória de perspectivas e lugares de fala (GUBA e LINCOLN, 2004). Essas propostas de olhares carregam vias não-hierarquizantes, não-binárias e interseccionais (AKOTIRENE, 2018) e, com isso, exercita o polidiálogo (NOGUERA, 2011), um campo em que há vários centros, lugares de fala respeitados e com os devidos recortes, dialogando e debatendo intelectualmente a resolução de desafios sociais compartilhados.

Carr e Kemmis (2007) postulam uma característica que não deve ser omitida: advocacy e ativismo também são conceitos-chave nesse paradigma. O investigador é sujeito no papel de participante e facilitador nesse processo - com todos os riscos que são inerentes a isso. De acordo com Guba e Lincoln (1994, p. 115), no construtivismo a voz do investigador é a do "participante apaixonado" empenhado em facilitar a reconstrução "multi-voz" de sua própria construção, bem como a de todos os outros participantes".

Não pretendemos aqui ser porta-vozes nem representantes das lideranças periféricas; falamos do lugar de pesquisadores com experiência empírica, ativistas e facilitadores legitimados por esse grupo - nomeado Potências Periféricas - ao lado de quem temos trabalhado, refletido, agido e aprendido ao longo de mais de um ano.

2 A edição referenciada aqui respeita fielmente a linguagem da autora, que muitas vezes contraria a gramática, incluindo a grafia e a acentuação das palavras, mas que por isso mesmo traduz com realismo a forma de o povo enxergar e expressar seu mundo. 


\section{FATORES CRITICOS DO INVESTIMENTO SOCIAL: UMA PERSPECTIVA DO OUTRO LADO DA PONTE}

Conforme mencionado anteriormente, três encontros e uma imersão realizadas com o grupo Potências Periféricas foram a base para este estudo. O primeiro encontro ocorreu na Prefeitura de São Paulo com líderes de dez organizações das cinco regiões da cidade, onde se discutiram os gargalos que impedem os recursos de chegar às periferias. A conversa abordou questões como: linguagens distintas usadas por financiadores e potenciais financiados, que impedem a boa comunicação entre os dois grupos; o fato de alguns territórios serem mais visíveis do que outros; o papel dos intermediários nos processos. Os demais encontros ocorreram no Centro de Formação e Pesquisa do Sesc, com a participação média de 14 coletivos, nos quais tratamos de ações a serem realizadas por meio de grupos de trabalho. Por fim, a imersão em maio de 2019 teve por objetivo fortalecer a rede e trocar conhecimentos e capacitação.

Após os encontros e a imersão, os encaminhamentos desenharam ações concretas, como a construção de um glossário elaborado em conjunto pelas organizações das periferias participantes do Potências, juntamente com os intermediários. No documento foram listadas expressões encontradas em regulamentos de conhecidos editais,

O Manifesto contempla recomendações para o investimento social nas periferias com sugestões, por exemplo, acerca de comunicação, burocracia, papel dos intermediários e composição das equipes de avaliação dos financiadores cuja complexidade ou derivação da língua inglesa comprometem o completo entendimento por parte de atores periféricos do que está sendo requisitado. Uma vez pronto o material, será realizada sua divulgação nas "quebradas", objetivando a "tradução" dos termos para o maior número de interessados, quebrando, assim, códigos que vêm dificultando a comunicação entre financiadores e potenciais financiados. Vale ressaltar que a comunicação é uma das chaves para o impacto coletivo.

O segundo documento, mais bem discutido nesta seção, constitui-se de recomendações e orientações aos financiadores, membros de institutos, fundações, empresas, governo etc. Elaborado ao longo dos grupos focais e validado por todas as organizações e coletivos participantes do Potências, o chamado FAQ das Periferias para Financiadores ou Manifesto contempla recomendações para o investimento social nas periferias com sugestões, por exemplo, acerca de comunicação, burocracia, papel dos intermediários e composição das equipes de avaliação dos financiadores. O Manifesto foi inicialmente redigido pelos autores deste artigo e, inicialmente validado, atualmente passa por revisão de todos os coletivos ${ }^{3}$.

É desse processo de um ano que emergem dois fatores críticos de sucesso para o ISP na perspectiva de lideranças de coletivos periféricos, recortados da análise de mais de 32 horas de conversas, reflexões, depoimentos e entrevistas sistematizados: o primeiro relacionado a mudanças de aspectos culturais e comportamentais por parte dos financiadores; o segundo a respeito de aspectos técnicos e táticos do cotidiano da parceria entre investidores e investidos.

No caso de fatores culturais e comportamentais, foi possível identificar três aspectos centrais e urgentes para estreitar a distância de cada lado da ponte: mudança de paradigma, saber como e visão empática. Desses aspectos decorre uma matriz com 12 fatores críticos, na visão das lideranças periféricas (Figura 1).

\footnotetext{
3 No momento de fechamento deste artigo (setembro/outubro de 2019), cerca de dez organizações e coletivos haviam confirmado presença para o quarto encontro, em que seria discutida a implantação de um novo processo de governança, com facilitação feita pelas próprias lideranças periféricas, contando com os intermediários somente como apoio. Três organizações e coletivos se ofereceram para estar na gestão do grupo, realizando a produção e a comunicação do evento de forma autônoma e colaborativa. Compreendemos que essa trajetória deve ser feita de forma participativa, mas também com autonomia e protagonismo de quem realiza as ações de transformação nos territórios periféricos.
} 


\section{Figura 1 - Fatores culturais e comportamentais}

\section{Mudança de paradigma}

Desenvolver na equipe

do investidor uma visão

crítica sobre a posição do

financiador no mundo: como

estabelecer uma relação

de confiança em lugar da

abordagem colonizadora,

de cima para baixo?

\begin{abstract}
Ter uma real abertura para
a experimentação e o erro,

tratando o investimento

social nas quebradas

como um investimento

arrojado - mas mais

efetivo no longo prazo.
\end{abstract}

Questionar-se sobre

relevância versus

paradigma da inovação:

como financiador, você

está buscando a sedutora

inovação disruptiva e/

ou olhando para uma

demanda real e relevante do

território?
Construir programas a partir dos saberes e conhecimentos dos colaboradores que de fato conhecem as realidades das periferias (e não da perspectiva exclusiva dos escritórios em bairros nobres, bem intencionada mas, muitas vezes, infundada).

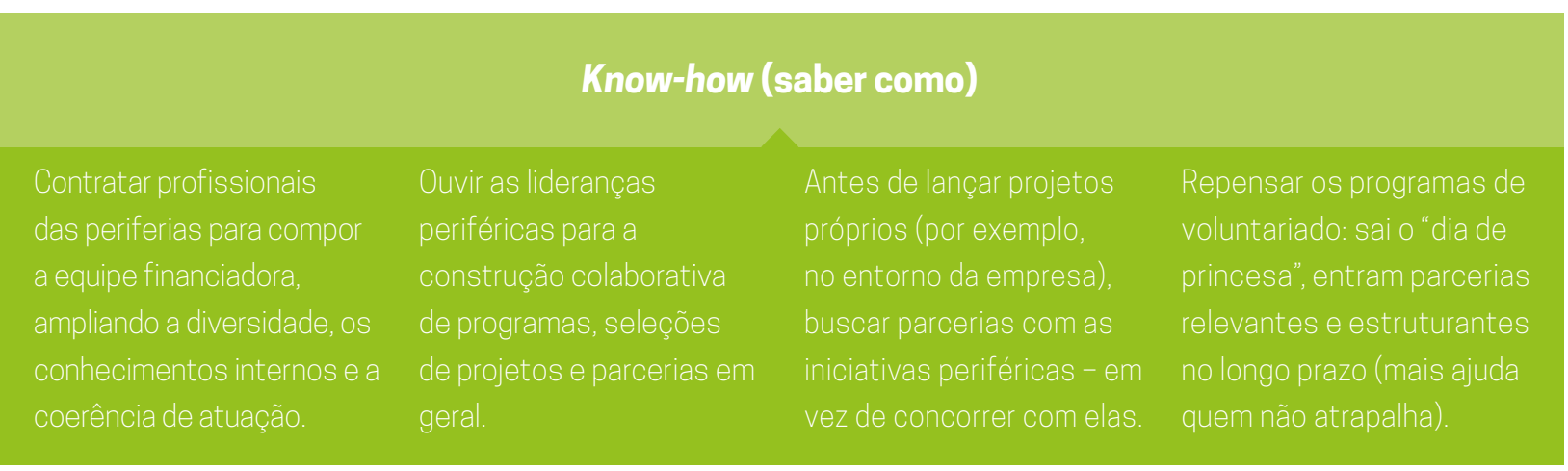

\begin{tabular}{|c|c|c|c|}
\hline \multicolumn{4}{|c|}{ Visão empática } \\
\hline $\begin{array}{l}\text { Frequentar as regiões } \\
\text { periféricas, marcar } \\
\text { reuniões nas quebradas, } \\
\text { compreender a realidade } \\
\text { local faz toda a diferença } \\
\text { para a parceria e a } \\
\text { transformação social. }\end{array}$ & $\begin{array}{l}\text { Ter ciência da diferença } \\
\text { de estrutura e capacidade } \\
\text { operacional entre grandes } \\
\text { OSC consolidadas - que } \\
\text { muitas vezes se colocam } \\
\text { como porta-vozes das } \\
\text { periferias, mas não o são - } \\
\text { e iniciativas periféricas. }\end{array}$ & $\begin{array}{l}\text { Entender que os } \\
\text { contextos periféricos } \\
\text { variam de local para local, } \\
\text { de região para região. Em } \\
\text { São Paulo, por exemplo, } \\
\text { conhecem-se muitas } \\
\text { ações incríveis da zona } \\
\text { sul, mas pouco se fala } \\
\text { das norte e oeste, que } \\
\text { também apresentam } \\
\text { iniciativas de potência } \\
\text { (há uma desigualdade } \\
\text { proporcional na } \\
\text { destinação de recursos). }\end{array}$ & $\begin{array}{l}\text { Conversar com quem } \\
\text { já está apoiando essa } \\
\text { mudança de paradigma } \\
\text { no investimento social. É } \\
\text { uma troca ainda recente } \\
\text { e com muitos caminhos } \\
\text { a serem construídos } \\
\text { coletivamente, mas há } \\
\text { institutos e fundações } \\
\text { na vanguarda desse } \\
\text { processo, com } \\
\text { aprendizados relevantes. }\end{array}$ \\
\hline
\end{tabular}

Fonte: Elaboração própria.

Em relação ao segundo fator crítico, considerado "técnico", evidenciam-se também três aspectos centrais (comunicação, processos de seleção e relacionamento de parceria), compondo outra matriz de 12 fatores-chave (Figura 2). 


\section{Figura 2 - Fatores técnicos}

\section{Comunicação}

Ter cuidado com a linguagem (verbal e não verbal), "quebrando o código" para que todos os lados se entendam efetivamente.
Criar materiais de fácil leitura ou audiovisuais para facilitar o entendimento, de preferência validando com lideranças periféricas.
Estabelecer parcerias com coletivos de comunicação das periferias para que os editais e outras ações atinjam o público desejado.

\section{Processos de seleção}

Criar chamadas (como

editais) com foco específico

nas lideranças periféricas

(coletivos e movimentos,

inclusive - e sobretudo - os não

institucionalizados).
Simplificar as chamadas de

seleção (só pedir documentos

quando e se realmente

necessários, atentar para as

demandas não razoáveis)
Evitar abrir chamadas públicas para prospectar projetos tão fechados que no final viram um exercício impossível de adaptação - e consequente descaracterização - do projeto.

\begin{tabular}{|c|c|c|}
\hline & \multicolumn{2}{|l|}{ Relacionamento/ parceria } \\
\hline $\begin{array}{l}\text { Ter ciência e visão crítica acerca } \\
\text { do papel dos intermediários, que } \\
\text { podem ser qualificadores ou } \\
\text { atravessadores no processo de } \\
\text { acesso a recursos pelas periferias. }\end{array}$ & $\begin{array}{l}\text { Estar ciente de que não existe } \\
\text { colchão financeiro nas periferias } \\
\text { e que os atrasos nos repasses } \\
\text { têm consequências em escala } \\
\text { nos projetos. }\end{array}$ & $\begin{array}{l}\text { Tentar abrir caminhos na empresa } \\
\text { para também poder financiar } \\
\text { pessoas físicas (PF) e coletivos } \\
\text { não institucionalizados. }\end{array}$ \\
\hline $\begin{array}{l}\text { Oferecer sempre recursos } \\
\text { financeiros ao lado de formações, } \\
\text { construção de redes, mentorias, } \\
\text { oficinas etc.; ou seja, é preciso, } \\
\text { sim, oferecer sempre um aporte } \\
\text { financeiro quando se trata de } \\
\text { iniciativas individuais e ações } \\
\text { coletivas periféricas. }\end{array}$ & $\begin{array}{l}\text { Colocar-se no papel de articulador } \\
\text { com o poder público e outras } \\
\text { empresas para que as periferias } \\
\text { sejam ouvidas e tenham } \\
\text { condições de protagonizar a } \\
\text { transformação do território. }\end{array}$ & $\begin{array}{l}\text { Desburocratizar e tornar os } \\
\text { processos mais inteligentes e } \\
\text { empáticos faz bem para todos } \\
\text { os envolvidos: se para justificar } \\
\text { o recurso é necessário se } \\
\text { desviar do trabalho social, algum } \\
\text { problema há. }\end{array}$ \\
\hline
\end{tabular}

Fonte: Elaboração própria. 


\section{CONSIDERAÇÕES FINAIS}

Se as realidades forem observadas de forma estática, podem ser duras e inflexíveis. As respostas que encontramos neste estudo e, principalmente, na experiência com os representantes de coletivos e organizações do Potências Periféricas, nos trouxeram diversos aprendizados - e um dos primeiros é justamente acessar essas realidades diferentes e tratar desse cenário como periferias, no plural, pois estamos falando de territórios, atuações e histórias únicas, ainda que conectadas por aspectos de desigualdade e resistência. A partir disso, analisamos que todos os fatores e subfatores críticos de sucesso do investimento social nas periferias a partir da perspectiva das lideranças dos coletivos podem ser resumidos em duas palavras: empatia cultural e coerência técnica.

Para que a empatia aconteça, o primeiro passo, apontam os coletivos, é cruzar a ponte, como diz a letra da música Da Ponte pra Cá do Racionais MC’s: "não adianta querer, tem que ser, tem que pá, o mundo é diferente da ponte pra cá” (literalmente: no caso de São Paulo, das marginais; no Rio, das linhas Amarela e Vermelha). É a melhor forma de entender a realidade das quebradas, mudar paradigmas, desmistificar fantasias e pré-conceitos. É uma oportunidade para o investidor conhecer a potencialidade criativa e de transformação social que está acontecendo nas periferias, participando também desse movimento, como empresas e como cidadãos. Isso decerto permitirá a criação de programas mais robustos e efetivos.

Outro ponto fundamental que emerge é estabelecer uma comunicação franca, direta e transparente, coerente com o público, fundamental em qualquer relação. Uma melhor qualificação do investimento social pode emergir da forma como é comunicado. É importante refletir quais os meios de comunicação escolhidos para divulgar as chamadas (editais, desafios, premiações etc.), se a comunicação realmente chega até os públicos periféricos e quais linguagens e abordagens são utilizadas. Nem sempre os meios digitais (mídias sociais) são a forma efetiva de alcançar os públicos prioritários. É preciso investir esforços em uma comunicação mais pessoal e boca-a-boca, em muitos casos, com pé no chão e presença real nos territórios. Não significa que os financiadores necessitem fazer isso de forma unilateral: estabelecer parcerias com organizações já atuantes nas comunidades é fundamental para alcançar sucesso visando o impacto coletivo.

Além disso, é fundamental abrir diálogo e fomentar novas lideranças periféricas, gerando um ciclo virtuoso de transformação social diretamente com quem mais entende da realidade na qual se deseja incidir. Os investidores sociais têm a seu favor um contexto especial: a atuação crescente de coletivos e outras formas associativas, fenômeno que, se não é novo, hoje emerge com uma potência sem igual nos grandes centros urbanos. É necessário centrar esforços em mapear novas organizações e coletivos, (re)descobrindo continuamente as regiões periféricas - que apresentam profundas desigualdades entre elas próprias. Sabemos, por exemplo, que a zona Sul da cidade de São Paulo há décadas representa um terreno fértil em criatividade, cultura e transformação social da base para a base, mas existem movimentos sociais relevantes que ainda não foram descobertos em tantas outras regiões.

A coerência, afirmam as lideranças periféricas, tem muito a ver com quem está contando a história. Por exemplo, é crescente a movimentação de atores diversos em prol da cultura de doação no Brasil, inclusive com a participação de grandes empresas (e empresários), o que os coletivos reiteram ver com bons olhos. A ponderação é: em um contexto de discussões de endowments, plataformas de crowdfunding, crowd equity e outros estrangeirismos mais, doação para quem? De que forma será uma cultura de doação que chegará cada vez mais de fato a quem precisa, sem fomentar, por exemplo, organizações que se colocam, mas nem sempre são assim reconhecidas, como "porta-vozes das quebradas"? Como incluir a contribuição real das periferias nesse movimento, sem o vício colonizador que se perpetua desde as caravelas cabralinas? Nessa mesma perspectiva, negócios e investimentos de impacto são outro tema levantado, sobre os quais caberia outro artigo, a nosso ver.

Refletir sobre o poder de criar e contar histórias, como propõe Chimamanda Adichie, é ainda mais imprescindível no contexto atual, pois "como elas são contadas, quem as conta, quando são contadas e quantas são contadas depende muito de poder" (ADICHIE, 2019, p. 23) - e deve valer para todas as temáticas, entre as quais o ISP. Se o primeiro passo é o reconhecimento desse lugar, o próximo é estar aberto a fazer juntos - uma mudança de paradigma, portanto, desafiadora, mas possível e relevante.

Esperamos, com este estudo, em pleno desenvolvimento, já que seguimos participando de uma nova etapa do Potências Periféricas, contribuir para ampliar uma história a partir de novas e múltiplas histórias, de modo a fortalecer com equidade a narrativa do ISP nas periferias, não só de São Paulo, mas também de outros centros urbanos brasileiros. 


\section{REFERÊNCIAS}

ADICHIE, Chimamanda Ngozi. O perigo de uma história única. 1a edição. São Paulo: Companhia das Letras, 2019.

AKOTIRENE, Carla. O que é interseccionalidade? Belo Horizonte: Letramento; Justificando, 2018.

BARROS, Silvia. Quando o impacto é realmente coletivo? Associação Nacional por uma Economia de Comunhão (ANPECOM). 27 de março de 2019. Disponível em: http://www.anpecom.com.br/quando-o-impacto-e-realmente-coletivo/. Acesso em: $16 / 09 / 2019$.

BIEKART, Kees; FOWLER, Alan. A civic agency perspective on change. Development, n. 55, v. 2, p. 181-189, 2012. DOI: http://doi.org/10.1057/dev.2012.9.

BIEKART, Kees; FOWLER, Alan. Transforming activisms 2010+: exploring ways and waves. Development and Change, n. 44, v. 3, p. 527-546, 2013. DOI: http://doi.org/10.1111/dech.12032.

CARDOSO, Ruth. Movimentos sociais na América Latina. Revista Brasileira de Ciências Sociais, n. 3, v. 1, p. 27-37, 1987.

CARLOS, Euzeneia. Movimentos sociais: revisitando a participação e a institucionalização. Lua Nova, n. 84, p. 353-364, 2011. DOI: http://doi.org/10.1590/S0102-64452011000300011.

CARR, Wilfred.; KEMMIS, Stephen. Becoming critical: education, knowledge and action research. Londres: RoutledgeFalmer, 2007.

CASTELLS, Manuel. Opening: networking minds, creating meaning, contesting power. In: CASTELLS, Manuel. Networks of outrage and hope: social movements in the Internet age. p. 1-17. Cambridge: Polity Press, 2012.

DANTAS, Audálio. Prefácio: A atualidade do mundo de Carolina. In: JESUS, Carolina Maria. Quarto de despejo: diário de uma favelada. Ilustração de Vinicius Rossignol Felipe. 10a . ed. São Paulo: Ática, 2014.

GIFE - Grupo de Instituições, Fundações e Empresas. Censo GIFE. Disponível em: https://gife.org.br/censo-gife/. 2016. Acesso em: 16/9/2019.

FISCHER, Rosa Maria. Alianças e parcerias: um caminho para o desenvolvimento. In: FISCHER, Rosa Maria. O desafio da colaboração: práticas de responsabilidade social entre empresas e terceiro setor (1 ${ }^{\text {a }}$ ed.). p. 29-37. São Paulo: Gente, 2002.

GUBA, Egon G.; LINCOLN, Yvonna S. Competing paradigms in qualitative research. In: DENZIN, N. K.; LINCOLN, Y. S. (eds.). Handbook of qualitative research. Thousand Oaks, CA, EUA: Sage Publications, 1994, p. 105-117.

JESUS, Carolina Maria. Quarto de despejo: diário de uma favelada. Ilustração de Vinicius Rossignol Felipe. 10ª . ed. São Paulo: Ática, 2014.

LAVALLE, Adrian Gurza; CASTELLO, Graziela; BICHIR, Renata M. Quando novos atores saem de cena: continuidades e mudanças na centralidade dos movimentos sociais. Política e Sociedade, n. 5, p. 37-55, 2004.

KANIA, John; KRAMER, mark. Collective impact. Stanford Social Innovation Review, 2011. Disponível em: https://hbr. org/2011/01/the-big-idea-creating-shared-value. Acesso em: 20/09/2019.

NOGUERA, Renato. O ensino de filosofia e a lei 10.639. Rio de Janeiro: CEAP, 2011.

PAULA, Ana Paula Paes. Administração pública brasileira: entre o gerencialismo e a gestão social. Revista de Administração Pública, n. 45, v. 1, p. 36-49, 2005. DOI: http://doi.org/10.1590/S0034-75902005000100005.

PORTER, Michael; KRAMER, Mark. Creating shared value. Stanford Social Innovation Review, v. 9, n. 1, p. 36-41, 2011.

RACIONAIS MC's. 2002. Da ponte pra cá. In: Nada como um dia após o outro dia. [CD] São Paulo: Zimbabwe Records.

RIBEIRO, Alexandre. Reservado. Diadema: Miudeza/ LiteraRUA, 2019.

RIBEIRO, Djamila. O que é lugar de fala? Canal Curta! Especial Livros. 21 de dezembro de 2017. Disponível em: https://www. youtube.com/watch?v=S7VQ03G2Lpw. Acesso em: 16/09/2019.

SECCO, Lincoln. As Jornadas de junho. In: VAINER, Carlos. Cidades rebeldes: passe livre e as manifestações que tomaram as ruas do Brasil. São Paulo: Boitempo; Carta Maior, 2013, p. 66-73.

TEODÓSIO, Armindo. S. S. Organizações da sociedade civil. In: BOULLOSA, Rosana. (ed.). Dicionário para a formação em gestão social. Salvador: CIAGS/UFBA, 2014, p. 128-132. 
OS AUTORES

\section{Cássio Aoqui \\ cassio.aoqui@usp.br}

Mestre em Ciências e bacharel em Administração (FEA-USP), com especialização em Educação em Turismo (UnB) e professor de Inovação Social da Fundação Instituto de Administração (FIA), é diretorexecutivo da ponteAponte, consultoria especializada na qualificação do investimento social privado. Foi jornalista da Folha de S.Paulo por 11 anos, onde foi coidealizador da Rede Folha de Empreendedores Socioambientais. É editor de publicações pela Publifolha, Empreendedor Cívico da Rede de Ação Política pela Sustentabilidade (RAPS), fellow da 92 Y/Ford Fellowship e do Gaimusho (Ministério de Relações Exteriores do Japão), além de pesquisador no Centro de Empreendedorismo Social e Administração do Terceiro Setor (Ceats), ex-bolsista da Capes/CNPq e membro da International Society for Third Sector Research (ISTR).

\section{Diana Mendes dos Santos diana@ponteaponte.com.br}

Bacharel em Relações Internacionais e em Políticas Públicas pela Universidade Federal do ABC (UFABC), é coordenadora de projetos na ponteAponte, à frente de iniciativas como o Potências Periféricas (acesso a recursos nas periferias) e o Elas Periféricas (com foco em mulheres negras periféricas). É ativista do movimento negro, atuando como coordenadora de Monitoramento e Avaliação da rede Umunna, da qual é cofundadora, para fortalecimento de mulheres negras na política, especialmente na Campanha Mulheres Negras Decidem. Foi cofundadora e segue como apoiadora do Coletivo Negro Vozes da UFABC. Desenvolveu pesquisa científica pela CNPq, visando olhar para políticas públicas nas áreas periféricas. Atualmente, dedica-se a aprofundar estudos e leituras em indicadores sociais e avaliação sistêmica de projetos.

\section{artigos GIFE}




\title{
artigos GIFE
}

Supervisão: José Marcelo Zacchi e Gustavo Bernardino

Coordenação: Graziela Santiago

Produção editorial: Gleice Regina Guerra

Apoio: Carolina Magosso

Diagramação: Clarissa Sitó

Impressão: Forma Certa

ISSN: 2674-8061

DOI: doi.org/10.33816/gife.20190102a4

(C) 2019 GIFE - Grupo de Institutos Fundações e Empresas

\section{(C) (i) ()}

Este material é disponibilizado sob a licenca Creative Commons Atribuição Não Comercial 4.0 Internacional. http://creativecommons.org/licenses/by-nc/4.0

As opiniões e análises expressas nesta publicação não necessariamente refletem as do GIFE.

\author{
Apoio institucional \\ Fundação Ford \\ Fundação Lemann \\ Instituto C\&A \\ Instituto Unibanco
}

QGIFE 